\title{
The Progress in the Ongoing Development Work: Enhancement of Glucose Electro-Oxidation in Direct-Mode Fuel Cells - An Update
}

\author{
J.-P. Spets ${ }^{*, 1}$, M.J. Lampinen ${ }^{1}$, Y. Kiros ${ }^{2}$, T. Anttila ${ }^{3}$, J. Rantanen ${ }^{3}$, M.A. Kuosa ${ }^{1}$ and K. Saari ${ }^{1}$ \\ ${ }^{I}$ Helsinki University of Technology, Department of Energy Technology, Applied Thermodynamics, PO Box 4400, \\ FI-02150 TKK, Finland \\ ${ }^{2}$ Royal Institute of Technology-KTH, Department of Chemical Engineering and Technology, S100-44 Stockholm, \\ Sweden \\ ${ }^{3}$ Oy Hydrocell Ltd, Minkkikatu 1-3, FI-04430 Järvenpää, Finland
}

\begin{abstract}
This study deals with the R\&D regarding the direct glucose fuel cell with a capacity of increasing the power density with glucose as a fuel. The direct-mode fuel cell in which the fuel and the alkaline electrolyte are mixed with each other is tested at room temperature. The direct-mode fuel cell is exposed to an externally generated electromagnetic field with $4 \mathrm{GHz}$ sine signals between electrodes to cause both the splitting of the fuel molecule and the electrochemical oxidation. As a result from the use of the higher frequency signals, a maximum current density of $15 \mathrm{mAcm}^{-2}$ has been achieved with the total voltage of $0.5 \mathrm{~V}$.
\end{abstract}

Keywords: Direct-mode fuel cell, Glucose, Electrochemical reforming, Sine signal, Room temperature.

\section{INTRODUCTION}

The ideal way to use fuels in fuel cells for power generation systems is the direct use of a fuel like glucose in a liquid phase, whereas glucose is produced from cellulose by hydrolysis [1-4]. This allows easier use of the fuel. In directmode fuel cells (DMFC) in which a fuel and an aqueous electrolyte are mixed with each other the current densities have been very low. Depending on the $\mathrm{pH}$ value of the electrolytes, the current densities have ranged at room temperature from 0.8 to $11 \mathrm{mAcm}^{2-}$ [1-4], in comparison to current densities of several hundreds $\mathrm{mAcm}^{-2}$ in the direct fuel cells, which are supplied with either hydrogen or alcohols $[5,6]$. However, the use of direct-mode fuel cells is simpler because they are equipped only with metallic catalysts and without separators.

In this study a signal generator (SG), which produces the higher frequency sine signals than were early produced with the function generator (FG) [4], is used. The idea is to use the SG to produce a changing electromagnetic field between the electrodes [4]. The glucose molecule could start to vibrate and then split into smaller units in the electromagnetic field (i.e. electrochemical reforming). The operating capacities of the anode and cathode catalysts could also increase as a result from the increased activity towards the fuel molecules. The use of a monosaccharide glucose $\left(\mathrm{C}_{6} \mathrm{H}_{12} \mathrm{O}_{6}\right)$ fuel is of great importance, because it can be produced easily by catalytic hydrolysis at elevated temperatures at maximum $250{ }^{\circ} \mathrm{C}$ from both starch and cellulose (polysaccharides) [7, 8]. The target in this work is to continue the production of a direct-mode bioorganic fuel cell with an alkaline electro-

*Address correspondence to this author at the Helsinki University of Technology, Department of Energy Technology, Applied Thermodynamics, PO Box 4400, FI-02150 TKK, Finland; E-mail: jukka-pekka.spets@tkk.fi lyte and with increased power density of several $\mathrm{mWcm}^{-2}$. In this study, the electromagnetic signals with the higher frequency than in earlier studied are fed to the direct-mode fuel cell before the discharge of the DMFC to enhance the electrochemical oxidation of the glucose. An anode catalyst of platinum and palladium (Pt-Pd) and a combined cathode catalyst of cobalt porphyrin complex (CoTPP) and of spinel $\left(\mathrm{MnCo}_{2} \mathrm{O}_{4}\right)$ are used as catalyst materials in the test DMGC with an alkaline electrolyte.

\section{EXPERIMENTS}

\subsection{The Test Equipment}

The test fuel cell (FC) equipment, which has been used in the earlier tests [2-4], included a direct-mode fuel cell, a recirculation pump (capacity $100 \mathrm{ml} \mathrm{min}^{-1}$ ), an air fan and a recirculation tank (a glass bottle) for the fuel-electrolyte solution. The test fuel cell equipment and the electrical connections are shown in Fig. (1).

The direct-mode fuel cell in Fig. (1) consisted of a twocylinder structure, in which the inner cylinder was an anode electrode and the outer one was a cathode electrode [2-4]. The anode catalyst structure was wetted on both sides of the catalyst surfaces. The distance between the anode and cathode was $1 \mathrm{~mm}$. The catalyst loadings of the anode electrode were $2.46 \mathrm{mgcm}^{-2}$ for both the Pt and Pd in the bimetallic combination (in a weight ratio of 1:1) with concentrations of $10 \mathrm{wt} . \%$ on carbon. The catalyst loadings of the combined cathode electrode contained a catalyst loading of $3.15 \mathrm{mgcm}^{-}$ ${ }^{2}$ of CoTPP with a concentration of $18 \mathrm{wt}$. \% on carbon and of $17.5 \mathrm{mgcm}^{-2}$ of $\mathrm{MnCo}_{2} \mathrm{O}_{4}$. The anode electrode consisted of a single-layer structure without diffusion material. The cathode electrode was of the double-layer type containing both the active (catalyst) and the diffusion layers. The electrodes were sintered at a temperature of $350{ }^{\circ} \mathrm{C}$. The geomet- 

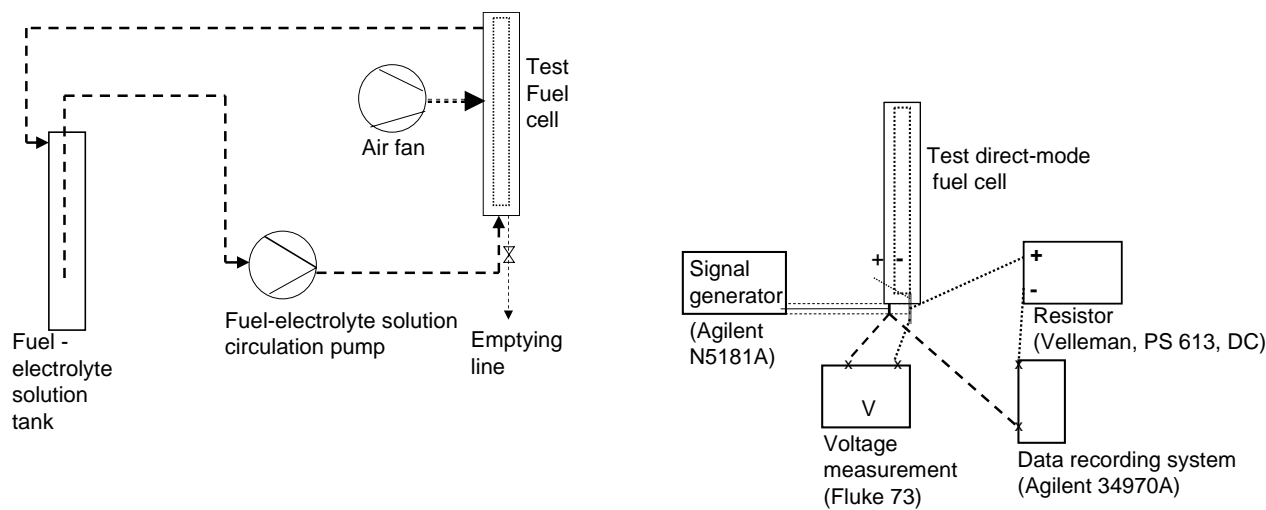

Fig. (1). The test fuel cell equipment (on the left) and the electrical connections (on the right).

ric areas of both electrodes were $200 \mathrm{~cm}^{2}$. The Pt-Pd catalyst was a commercial grade purchased from Johnson-Matthey. The CoTPP and the $\mathrm{MnCo}_{2} \mathrm{O}_{4}$ catalysts were commercial products obtained from Oy Hydrocell Ltd.

The electrical equipment in Fig. (1) include the electrodes, current/voltage measurements, resistor, and the signal generator. An auxiliary device (Velleman, PS 613, and DC) was used as an electrically controlled resistor. The voltage values were measured by Fluke 73 measurement. The current and voltage values were recorded with an Agilent 34970A data logger. The current was determined indirectly from the voltage loss over shunt with known voltage loss and current values $(60 \mathrm{mV}$ and $5 \mathrm{~A})$.

A SG of the Agilent N5181A type was used to create a changing electro-magnetic field over the electrolyte space in the fuel cell. A SG produced radio frequency (RF) signals, which were regarded as an alternating current (AC) signals. In the tests one type of electromagnetic signal (sine, AC of $0.6 \mathrm{~V}(+/-10 \%)$ with $4 \mathrm{GHz})$ was used. The current outputs were measured to be $20 \mathrm{~mA}$.

\subsection{Test Routine}

The test routine in the entire test was as follows: an aqueous alkaline $2 \mathrm{M}$ potassium hydroxide $(\mathrm{KOH}$, Sigma Aldrich) solution electrolyte was prepared. The fuel, glucose (anhydrous, Oriola), was added to the electrolyte in a concentration of $1 \mathrm{M}$. The electrolyte-fuel solution was added to the fuel cell. The air fan was started and the open-circuit voltage $(\mathrm{OCV})$ of the fuel cell was measured at room temperature $\left(20^{\circ} \mathrm{C}\right)$ until the generation rate decreased to a minimum value of 2 to $4 \mathrm{mVmin}^{-1}$. After the generation of OCV for a short period (i.e. 30 seconds) current was taken from the test fuel to secure that the catalysts were activated. The open-circuit generation was started again. The SG was connected to the test fuel cell with a coaxial cable: an internal wire was connected to a cathode electrode and the external insulator netting was connected to the anode electrode of the fuel cell. The signal generator was set to the values as a $\mathrm{AC}$ of $0.6 \mathrm{~V}(+/-10 \%, 4 \mathrm{GHz}$, sine $)$ and it was used for a period of 90 minutes, because it was assumed that a long enough reforming time was capable of causing the phenomena of both the electrochemical reforming and the splitting of the fuel molecule in the electrolyte. After the selected time period, the signal generator was switched off to avoid possible malfunctioning of the function generator when taking current from the test fuel cell. The polarisation curves and the current-versus-voltage values were recorded in each case. The test was stopped when the voltage of the direct-mode fuel cell decreased to a value of $0.5 \mathrm{~V}$ [2-4] to avoid alkaline penetration into the cathode electrode at lower voltage values.

The Coulombic efficiency (CE) values of each test were calculated using the recorded current and time values according to Equation 1 [9]:

$C E=\frac{\left(M_{w} ! I d t\right) 100 \%}{F n_{e} V_{a n} \# C}$

In Eq. (1) $M_{w}$ is the molecular weight of glucose, $n_{e}$ is the number of electrons transferred, $V_{a n}$ is the volume of liquid in the anode $\left(0.3 \mathrm{dm}^{-3}\right), \mathrm{F}$ is the Faraday constant $(96500$ $\mathrm{As} / \mathrm{mol}$ ), and $\Delta \mathrm{C}$ is a change in the substrate mass concentration $\left(\mathrm{C}_{0}-\mathrm{C}\right) . \Delta \mathrm{C}=\mathrm{C}_{\mathrm{o}}$ was used in this study. In Eq. (1) the term (JIdt) corresponds to the integration of the recorded Coulombs, and the denominator corresponds to the maximum available Coulombs from the initial glucose molar amount in the aqueous electrolyte.

\section{RESULTS AND DISCUSSION}

\subsection{Measurements}

Fig. (2) shows the measured polarisation curves with glucose as the fuel in the alkaline electrolyte. The tests were conducted at room temperature. The measured current values were then compared to the values, which have been reported earlier [2-4] without and with the use of the function generator FG with lower frequency signals $(20 \mathrm{kHz})$.

The measured polarisation curve at a temperature of $20{ }^{\circ} \mathrm{C}$ in Fig. (2) shows a relatively high difference when compared to the earlier work with FG sine signals at the frequency of $20 \mathrm{kHz}$ [4]. The use of the higher frequency sine signals from $20 \mathrm{kHz}$ to $4 \mathrm{GHz}$ has enabled a noticeable increase in the maximum current density value from earlier reported $11 \mathrm{~mA} \mathrm{~cm}^{-2}$ to $15 \mathrm{~mA} \mathrm{~cm}$ (at voltage of $0.5 \mathrm{~V}$ ). The OCV value $0.87 \mathrm{~V}$ at $20^{\circ} \mathrm{C}$ shows the same value as that in the earlier tests with the use of the lower frequency FG sine signals [4]. The capacity test of the DMFC after the use of the SG (with AC sine signals) is shown in Fig. (3). The voltage values of the fuel cell were recorded with changing current intervals. The capacity recordings were calculated 


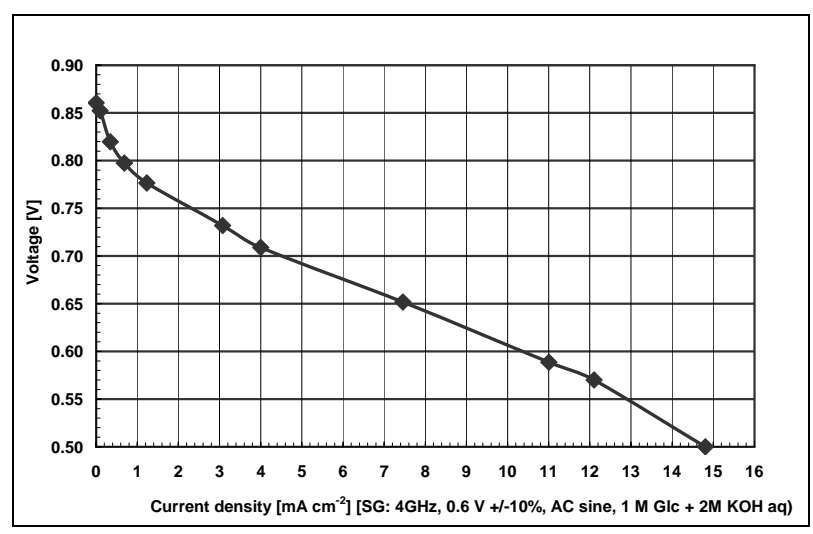

Fig. (2). Polarisation curves of direct-mode alkaline FC after the use of signal generator with AC sine signals.

from the linked runs as follows: first the polarisation curve (Fig. (2)) was determined and then the capacity test (Fig. (3)) was repeated several times until the decreases in the voltage values from each $\mathrm{OCV}$ values until the value of $0.5 \mathrm{~V}$ were noticed (Fig. (3)).

From the results shown in Fig. (3) it can be concluded that when the higher frequency sine signals are used the maximum current density value of the DMFC increases as compared to earlier tests [4]. At $20{ }^{\circ} \mathrm{C}$ the current density value at a voltage of $0.5 \mathrm{~V}$ increases from $11 \mathrm{mAcm}^{-2}$ (i.e. $2.2 \mathrm{~A} \mathrm{[4])} \mathrm{to} 15 \mathrm{mAcm}^{-2}$ (i.e. $3 \mathrm{~A}$ ) with the use of $4 \mathrm{GHz}$ sine
AC signals, i.e. an increase of $36 \%$ was reached when compared to the earlier use of $20 \mathrm{kHz}$ sine signals [4].

The recorded Coulombs for the experimental tests and the evaluation of the $\mathrm{CE}$ value for the fuel cell according to Eq. (1) are shown in Table 1. The CE value was calculated as a ratio to theoretical value when two electrons are supposed to be released from one molecule in the electrochemical oxidation (i.e. glucose is oxidised to gluconic acid).

The recorded Coulombs and Coulombic efficiency values (CE) in Table 1 show higher values than it was reported in

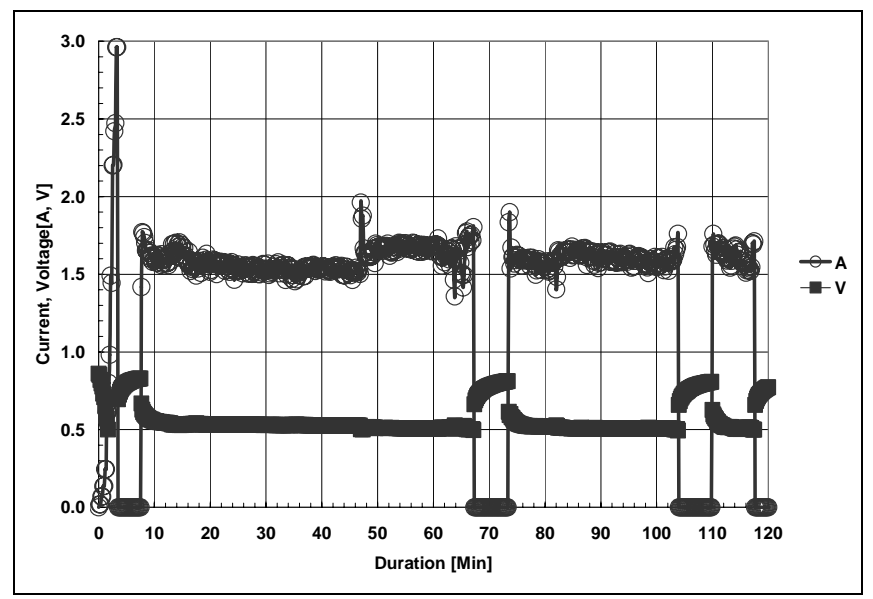

Fig. (3). The capacity test of the direct-mode fuel cell at $20{ }^{\circ} \mathrm{C}$ after the use of the signal generator with $\mathrm{AC} 4 \mathrm{GHz}$ sine signals.

Table 1. Recorded Coulombs for the Experimental Tests and the CE Values as Ratio to Theoretical Value with the Release of Two Electrons Per Fuel Molecule

\begin{tabular}{|c|c|c|}
\hline Temperature $\left({ }^{\circ} \mathrm{C}\right) /$ Signal & Coulombs (As) & CE (\%) \\
\hline \hline $20 /$ Sine AC & 9600 & 16.6 \\
\hline
\end{tabular}


earlier tests, when the function generator with $20 \mathrm{kHz}$ sine signals was used at $20{ }^{\circ} \mathrm{C}$ (i.e. $2778 \mathrm{As}, \mathrm{CE}=4.8 \%$ [4]). The increase of $245 \%$ in the recorded Coulombs was detected. Thus the higher frequency signals enable the achievement of higher current values possible.

By using the relative change in the COD value of the fuel-electrolyte solution in earlier studies, the number of transferred electrons per glucose molecule was approximated to be as two [4]. This is valid also for this study.

The current densities of the DMFC shown in Fig. (2) are still lower when compared to those observed in direct fuel cells (hydrogen- or alcohol-fed) with membranes [5, 6], but higher than those reported current density values obtained for microbial and enzymatic biofuel cells $[10,11]$. However, the DMFC is simple to use and provides good application potentials for small portable applications. The glucose fuel, which is produced from cellulose materials, provides a good alternative to alcohols (methanol and ethanol), because of its renewable and sustainable nature. There are problems in the direct use of methanol and ethanol because of the carbonisation problems in alkaline electrolytes, when the high current densities are to be extracted $[12,13]$. It is also assumed that the use of a SG with a different voltage and a higher signal frequency will cause the release of more than two electrons per glucose molecule in electro-chemical oxidation. If the electron yield from one molecule of glucose increases from 2 towards the 24 available electrons, glucose will be a good choice as a fuel for the low-temperature direct -mode fuel cell [4].

\subsection{Further Development Works in the Future}

The AC signals from the SG have to have higher frequency value than $4 \mathrm{GHz}$ to provide higher current densities in the direct-mode fuel cell. The search for more active catalyst materials for both the anode and cathode electrodes could also improve the operating capacity of the DMFC. Also after the optimisation of the other operational parameters (temperature and concentrations of fuel-electrolyte components) the production of both the higher current densities and of the number of Coulombs could be possible to achieve.

\section{CONCLUSIONS}

In this study a glucose was used in testing the directmode fuel cell connected to a signal generator. It was found that glucose in an aqueous alkaline electrolyte produced current density values of $15 \mathrm{mAcm}^{-2}$ at a voltage of $0.5 \mathrm{~V}$. This current density was higher than it was reported earlier after the use of a lower frequency sine signals from a function generator. It is still assumed that the frequency of the signals has to be increased much more from the value of $4 \mathrm{GHz}$ to cause a noticeable increase in the current density and the capacity values of the direct-mode glucose fuel cell. The influence of the signal generator on the operation of the direct-mode fuel cell is assumed to be increased more by the optimisation of the signal parameters together with the operating temperature and the component concentrations in the fuel-electrolyte solution.

\section{ACKNOWLEDGEMENTS}

This work is supported by the Finnish Funding Agency for Technology and Innovation (TEKES) and by Finnish partners (UPM, St-1 Biofuels, Diarc, Hydrocell and the Finnish Research Centre (VTT)). The research team in COST Action 543 is also acknowledged.

\section{REFERENCES}

[1] Spets, J.-P.; Kiros, Y.; Noponen, T.; Kuosa, M. A.; Rantanen, J. Lampinen, M. J.; Saari, K. Direct-mode glucose fuel cells with near-neutral-state electrolytes: Anode electrode studies with different catalysts and electrolytes. Open Fuels Energy Sci. J., 2009, 2, 82-86.

[2] Spets, J.-P.; Kiros, Y.; Kuosa, M. A.; Rantanen, J.; Sallinen, J.; Lampinen, M. J.; Saari, K. Starch and cellulose as fuel sources for low temperature direct mode fuel cells. Open Fuel Cells J., 2008, 1 , 1-3.

[3] Spets, J.-P.; Kuosa, M.; Granström, T.; Kiros, Y.; Rantanen, J.; Lampinen, M. J.; Saari, K. In: Thermec 2009, Proceedings data not yet available. Will be published in Dec 2009, Berlin, Germany, August 25-29; 2009.

[4] Spets, J.-P.; Kuosa, M. A.; Kiros, Y.; Anttila, T.; Rantanen, J.; Lampinen, M. J.; Saari, K. Enhancement of glucose electrooxidation by an external electromagnetic field in direct-mode fuel cells. J. Power Sources, 2010, 195, 475-479.

[5] Nagarale, R. K.; Gohil, G.S.; Shahi, V. K. Recent developments on ion-exchange membranes and electro-membrane processes. Adv. Colloid Interface Sci., 2006, 119, 97-130.

[6] Hou, H.; Sun, G.; He, R.; Wu, Z; Sun, B. Alkali doped polybenzimidazole membrane for high performance alkaline direct ethanol fuel cell. J. Power Sources, 2008, 182, 95-99.

[7] Dhepe, P. L.; Fukuoka, A. Cracking of cellulose over supported metal catlysts. Catal. Surv. Asia, 2007, 11, 186-191.

[8] Lin, Y.-C.; Huber, G. W. The critical role of heterogeneous catalysis in lignocellulosic biomass conversion. Energy Environ. Sci., 2009, 2, 68-80

[9] Logan, B. E. Microbial Fuel Cells. Wiley-Interscience: New Jersey, 2008.

[10] Bullen, R. A.; Arnot, T. C.; Lakeman, J. B.; Walsh, F. C. Biofuel cells and their development. Biosens. Bioelectron., 2006, 21, 2015 2045.

[11] Rabaey, K.; Verstraete, W. Microbial fuel cells: novel biotechnology for energy generation. Trends Biotechnol., 2005, 23, 291-298.

[12] Verma, A.; Basu, S. Short communication: Direct alkaline fuel cell for multiple liquid fuels. J. Power Sources, 2007, 174, 180-185.

[13] Verma, A.; Basu, S. Direct use of alcohols and sodium borohydride as fuel in an alkaline fuel cell. J. Power Sources, 2005, 145, 282285. 